\title{
The Impact of a Multidisciplinary Approach Protocol and Integrated Guidelines for Antibiotic Prophylaxis in Plastic Surgery Procedures
}

\author{
Isa AlAlwani*, Hasan AlTahoo, Fatima Yaqoob, Fatema Ahmed Ali, Sadeq Alekri
}

1. Department of Plastic Surgery, Salmaniya Medical Complex, Manama, Kingdom of Bahrain

\section{${ }^{*}$ Corresponding Author:}

Mr. Isa Al-Alwani

Plastic and Reconstructive Surgery Specialist Registrar Trainee

The Welsh Centre for Burns and Plastic Surgery

The United Kingdom

Email: Isaplasticsurgeon@gmail.com

Receive: 25 Nov 2020

Revise: 26 February 2021

Accept: 6 August 2021

\section{ABSTRACT}

\section{BACKGROUND}

Surgical antibiotic prophylaxis has been widely used for prevention of surgical site infections (SSI's). World Health Organization (WHO) global guidelines strongly recommend the administration of pre-operative prophylactic antibiotic, depending on the type of surgery, to reduce SSI's. However, within Gulf Cooperation Council (GCC) countries, antibiotic resistance has been rising due to unregulated prescribing practice. We aimed to assess adherence to local/ international guidelines in the plastic surgery unit of Salmaniya Medical Complex.

\section{METHODS}

This study was a retrospective review of adults' undergoing plastic surgery between the dates of $1^{\text {st }}$ of January 2019 to $30^{\text {th }}$ of April 2019. Recommendations and guidelines were provided by South Australian Guidelines for Surgical Antimicrobial Prophylaxis, NHS Greater-Glasgow Foundation Trust. Salmaniya Medical Complex Guidelines were also taken into consideration. This was followed by an implementation of standardized guidelines and a re-assessment period for another four months.

\section{RESULTS}

There were 106 patients who met the inclusion/exclusion criteria throughout the primary cohort. With respect to choice and dose of antibiotics, only 21 (19.8\%) of the procedures were adherent to global/local guidelines. Similarly, only $11.5 \%$ of those cases have met the recommended timing for pre-operative antibiotic administration. After the implementation period, adherence to guidelines regarding choice and time of antibiotic administration has increased to $36.8 \%$ and $32.6 \%$ respectively. SSI decreased from $1.8 \%$ to $0.08 \%$.

\section{CONCLUSION}

Practice in SMC in plastic surgery pre-operative antibiotic prophylaxis shows poor compliance to both local and international guidelines in terms of choice, dose, and time of administration. We were able to significantly improve adherence to international/local practice in both areas by implementing an integrated protocol in liaison with the medical staff involved in the plastic surgery unit and operating theatres.

\section{KEYWORDS}

Plastic surgery; Surgical site infections; Wound infections; Guidelines; Protocol; Aesthetic; Antibiotic prophylaxis

\section{Please cite this paper as:}

AlAlwani I, AlTahoo H, Yaqoob F, Ahmed Ali F, Alekri S. The Impact of a Multidisciplinary Approach Protocol and Integrated Guidelines for Antibiotic Prophylaxis in Plastic Surgery Procedures. World J Plast Surg. 2021;10(2):54-62.

doi: $10.29252 /$ wjps. 10.3 .54 


\section{INTRODUCTION}

Surgical Site Infection (SSI) refers to an infection that takes place post-operatively involving the part of the body where the surgery took place. SSI is a main factor that increases hospitalization being the third most frequent cause of nosocomial infection and affecting $16 \%$ hospitalized in-patients. In surgical patients, SSIs accounted for $77 \%$ of deaths due to post-operative complications ${ }^{1}$. As one of the most important medical measures to reduce SSIs, the WHO global guidelines strongly recommend the administration of pre-operative prophylactic antibiotic depending on the type of surgery ${ }^{2}$.

Within the literature, the effectiveness of preoperative antibiotics in preventing post-operative infections in plastic surgery operations has been widely demonstrated ${ }^{3-6}$. One particular study has illustrated that in clean contaminated procedures, prophylactic antibiotics prevents wound dehiscence, bone mal-union, stitch and septal abscesses ${ }^{7}$. One prospective observational study shows that the incidence of postoperative infections in nonantibiotic groups reach up to $42 \%$ compared to $8.9 \%$ in antibiotic groups ${ }^{3}$.

Despite that, there is a growing antibiotic crisis with new strains of drug resistant bacteria encountered in wounds ${ }^{8}$. Within Gulf Cooperation Council (GCC) countries, antibiotic resistance has been rising compared to European countries, due to unregulated prescribing practice and unaudited use of antibiotics ${ }^{9}$. As a result, there is a definite need to regulate the use of prophylactic antibiotics through implementing local/international guidelines.

In plastic surgery surgical prophylaxis, there is a customization of guidelines in different countries and hospitals based on local resistance patterns and types of pathogens. However, there are some common relations between most guidelines. Many guidelines, like the National Health Service (NHS) and South Australia guidelines, agree on the need of antibiotic prophylaxis on clean-contaminated, contaminated and dirty procedures ${ }^{10-12}$. In addition, there is evidence that antibiotics are not recommended for clean procedures ${ }^{10-13}$.

We aimed to evaluate the adherence and accuracy of giving peri-operative antibiotic prophylaxis in plastic surgery with respect to local/global guidelines, in the largest hospital in the Kingdom of Bahrain, Salmaniya Medical Complex.

\section{METHODS}

\section{Design and standards}

This study was a retrospective, standards based clinical review, evaluating peri-operative antibiotics given to all the patients who underwent operations in the plastic surgery unit in Salmaniyya Medical Complex between the $1^{\text {st }}$ of January 2019 and the $30^{\text {th }}$ of April 2019. The local guidelines on surgical antibiotic prophylaxis by Salmaniya Medical Complex was used as the main standard in this study ${ }^{14}$. Recommendations provided by NHS Salisbury ${ }^{15}$, NHS Greater Glasgow Foundation Trust guidelines ${ }^{16}$, and South Australian guidelines for Surgical Antimicrobial Prophylaxis ${ }^{17}$ were adopted where the local guidelines were insufficient.

Study settings and inclusion and exclusion criteria All adult and pediatric cases (of 1 year or more), who underwent plastic surgery operations under general anesthesia, over the four-month period between the $1^{\text {st }}$ of January 2019 and the $30^{\text {th }}$ of April 2019 were reviewed. Guidelines were implemented after the initial assessment period and were reassessed between the dates of $1^{\text {st }}$ September 2019 to $31^{\text {st }}$ December 2019. SEP Patients who underwent surgery under local anesthesia, received antibiotics as treatment, had incomplete data; were excluded from the study.

\section{Data collection and analysis}

The data collection included three main categories. The first category was patient demographics and medical background. This included patient identification, age, ethnicity, weight (in kilograms), known allergies and history of adverse reactions to antibiotics, colonization with resistant organisms and chronic comorbidities. The second category was operation details; where details of the operation performed, classification, type of anesthesia used, name of operating surgeon, time of the surgical incision and duration of the operation were noted. The third category was the choice of antibiotic prophylaxis (peri-operative and post-operative) administered including the name, dose, time of administration and reason for administering/ withholding a particular drug as antibiotic prophylaxis.

Data from electronic and written hospital files were directly plotted into an Excel spreadsheet by the authors. Nepitional ID numbers of cases in the inclusion criteria were recorded from the plastic surgery department and were used to access patient files. Data analysis was completed through Excel (2016 version).

\section{Implementation period and re-assessment}

Results obtained during the first study period were used to design a quality improvement strategy. An implementation period of three months was given, after which, a retrospective re-assessment was conducted using the same methodology from $1^{\text {st }}$ September to $31^{\text {st }}$ December 2019. 


\section{RESULTS}

The study took place over a period of one year, which included a three-month period for quality improvement strategies implementation. A total of 236 patients were admitted to the Plastic Surgery Department in Salmaniyya Medical Complex. Out of these cases, 112 had undergone operations/ procedures under general anesthesia and received prophylactic antibiotics. After removal of patients with incomplete documented data, a total of 106 patients were included in the primary study. During the 3 months from Sep to Dec 2019, 117 patients met the criteria and were included in the re-assessment period.

\section{Operation Classification}

Within plastic surgery, operations are generally classified into four types: clean, clean-contaminated, contaminated, and dirty. For the purpose of this study, clean procedures have been further divided into aesthetic (abdominoplasties, liposuction, breast surgeries, and implant insertions), uninfected burns (with or without skin grafts), and others (no involvement of implants, grafting, or open fractures). The procedures analyzed during the study period are described in table one (Table 1).

\section{Choice of prophylactic peri-operative antibiotics}

In all operations accounted for in the primary study, only $19.8 \%$ of the cases were given appropriate antibiotic prophylaxis consistent with local and international guidelines (Table 2). In specific: clean, clean-contaminated and dirty operations were given prophylaxis appropriately in 15.5\%, $0 \%$, and $100 \%$ respectively. In comparison, within the re-assessment study clean, clean-contaminated and dirty procedures had adherence of $31.8 \%, 0 \%$ and $100 \%$ respectively. Intravenous route was used in administering peri-operative antibiotics in all operations (Table 3 ).

\section{Clean operations}

In peri-operative prophylaxis of aesthetic procedures, our local hospital guidelines encourage a single dose of cefazolin $1 \mathrm{~g}$ IV as a STAT dose. Out of 69 patients undergoing aesthetic surgeries in the primary study, 65 patients were prescribed antibiotics pre-operatively as required. However, the antibiotics prescribed in all cases were not the antibiotic of choice. All cases were prescribed either ceftriaxone (third generation antibiotic) or cefuroxime (second generation antibiotic) (Table 4). Additionally, it is noteworthy that all cases had been prescribed an additional course of oral cefuroxime post-operatively, which is not in accordance with current best practice. With regards to uninfected burns, 7 cases $(70 \%)$ were not prescribed any prophylaxis. On the contrary, only three cases where given prophylactic perioperative antibiotics (Table 4 and 5). Yet, the prophylactic antibiotic was not the antibiotic of choice (Table 4). Other clean procedures that do not require peri-operative prophylaxis, under local and NHS guidelines, include excision of skin lesions/keloids/cysts, cut wounds and hand surgeries. Within the primary study, 28 clean procedures fit this category, 14 of which were treated with adherence to guidelines by not being prescribed prophylactic antibiotics. On the contrary, the other four procedures were prescribed antibiotics unnecessarily.

In aesthetic operations and uncomplicated burns, our facility's practice was not adherent to current practice. On the contrary, other simple clean procedures had adherence of $83 \%$ to guidelines during the primary study (Table 5). During the reassessment period, aesthetic procedures, uninfected burns and other clean procedures had an adherence of $23 \%, 63 \%$ and $59 \%$ respectively. Any operation where choice of antibiotic prophylaxis was not adherent to guidelines, the dose of antibiotic was not assessed (Table 5).

Table 1: Total number of operations and their classification included in the study

\begin{tabular}{lcccc}
\hline & \multicolumn{2}{c}{ Primary Study } & \multicolumn{2}{c}{ Re-assessment } \\
\hline Operation Classification & $\begin{array}{c}\text { Number of } \\
\text { operations }\end{array}$ & Total operations & Number of & Total operations \\
operations & $(\%)$ \\
$\quad$ Aesthetic & 69 & $(\%)$ & 70 & 60 \\
Uncomplicated burns & 10 & 65 & 15 & 13 \\
other & 18 & 9 & 22 & 19 \\
Clean / contaminated & 3 & 3 & 1 & 1 \\
Contaminated & 0 & 0 & 0 & 0 \\
Dirty & 6 & 6 & 9 & 100 \\
Total & 106 & 100 & 117 & 8 \\
Total number of operations included throughout this study and their relevant operation classification. The operations have been expressed \\
in numbers and percentage
\end{tabular}


Table 2: Adherence to guideline standards in the primary and re-assessment durations of the study.

\begin{tabular}{|c|c|c|c|c|}
\hline Guideline Standards & \multicolumn{2}{|c|}{ Primary Study Results } & \multicolumn{2}{|c|}{ Re-assessment Results } \\
\hline \multicolumn{5}{|c|}{ Choice of antibiotics and dose } \\
\hline \multicolumn{5}{|c|}{ Clean Operations } \\
\hline $\begin{array}{l}\text { 1.1 For aesthetic procedures including abdominoplasties, } \\
\text { liposuction, breast surgeries, and implant insertions, all cases are } \\
\text { to be given a single dose of prophylactic antibiotics. }\end{array}$ & $65 / 69$ & $94 \%$ & $70 / 70$ & $100 \%$ \\
\hline $\begin{array}{l}\text { 1.2 For aesthetic procedures including abdominoplasties, } \\
\text { liposuction, breast surgeries, and implant insertions: cefazolin } 1 \mathrm{~g} \\
\text { IV STAT is the prophylactic antibiotic of choice }\end{array}$ & $0 / 65$ & $0 \%$ & $16 / 70$ & $23 \%$ \\
\hline $\begin{array}{l}\text { 1.3 For burns requiring any type of surgical intervention: all cases } \\
\text { are to be given a single dose of prophylactic antibiotics. }\end{array}$ & $4 / 10$ & $40 \%$ & $8 / 15$ & $53 \%$ \\
\hline $\begin{array}{l}\text { 1.4 For burns requiring any type of surgical intervention: single } \\
\text { dose of flucloxacillin } 1 \mathrm{~g} \text { IV pre-operatively }\end{array}$ & $0 / 4$ & $0 \%$ & $5 / 8$ & $63 \%$ \\
\hline $\begin{array}{l}\text { 1.5 For clean operations that do not involve implants, grafting, or } \\
\text { open fractures: no antibiotic prophylaxis is required }\end{array}$ & $15 / 18$ & $78 \%$ & $13 / 22$ & $59 \%$ \\
\hline Total adherence in clean operations & $15 / 97$ & $15.5 \%$ & $34 / 107$ & $31.8 \%$ \\
\hline \multicolumn{5}{|c|}{ Clean-contaminated Operations } \\
\hline $\begin{array}{l}\text { 2.1 For clean-contaminated procedures all cases are to be given a } \\
\text { single dose of prophylactic antibiotics }\end{array}$ & $3 / 3$ & $100 \%$ & $1 / 1$ & $100 \%$ \\
\hline $\begin{array}{l}\text { 2.2 For clean-contaminated procedures involving cleft lip/palate } \\
\text { in pediatric : all cases are to be given a single dose of co- } \\
\text { amoxiclav } 30 \mathrm{mg} / \mathrm{kg}\end{array}$ & $0 / 3$ & $0 \%$ & $0 / 1$ & $0 \%$ \\
\hline \multicolumn{5}{|c|}{ Dirty Operations } \\
\hline $\begin{array}{l}\text { 3.1 For dirty procedures antibiotics are to be given therapeutically } \\
\text { depending on culture and sensitivity. }\end{array}$ & $6 / 6$ & $100 \%$ & $9 / 9$ & $100 \%$ \\
\hline TOTAL ADHERENCE TO GUIDELINES & $21 / 106$ & $19.8 \%$ & $43 / 117$ & $36.8 \%$ \\
\hline \multicolumn{5}{|c|}{ Time of administration of prophylactic antibiotics } \\
\hline $\begin{array}{l}\text { 4.1 Prophylactic antibiotics should be administered within one } \\
\text { hour prior to surgical incision. All antibiotic administration must } \\
\text { be complete at time of surgical incision }\end{array}$ & $8 / 69$ & $11.5 \%$ & $31 / 95$ & $32.6 \%$ \\
\hline
\end{tabular}

Table 3: Level of compliance in the all classes of operations in primary study and re-assessment period.

\begin{tabular}{|c|c|c|c|c|c|c|}
\hline \multicolumn{7}{|c|}{ Antibiotic prophylaxis - adherence to guidelines } \\
\hline & \multicolumn{2}{|c|}{ Clean } & \multicolumn{2}{|c|}{ Clean-contaminated } & \multicolumn{2}{|c|}{ Dirty } \\
\hline & $\begin{array}{c}\text { Primary } \\
\text { Study }\end{array}$ & $\begin{array}{c}\mathrm{Re}- \\
\text { assessment }\end{array}$ & $\begin{array}{c}\text { Primary } \\
\text { Study }\end{array}$ & $\begin{array}{c}\mathrm{Re}- \\
\text { assessment }\end{array}$ & $\begin{array}{c}\text { Primary } \\
\text { Study }\end{array}$ & $\begin{array}{c}\text { Re- } \\
\text { assessment }\end{array}$ \\
\hline $\begin{array}{l}\text { Total number of } \\
\text { operations }(n)\end{array}$ & 97 & 107 & 3 & 1 & 6 & 9 \\
\hline $\begin{array}{l}\text { Compliant antibiotic } \\
\text { prophylaxis use }(n)\end{array}$ & 15 & 34 & 0 & 0 & 6 & 9 \\
\hline $\begin{array}{l}\text { Non-compliant } \\
\text { antibiotic prophylaxis } \\
\text { use (n) }\end{array}$ & 82 & 73 & 3 & 1 & 0 & 0 \\
\hline $\begin{array}{l}\text { Adherence to } \\
\text { guidelines (\%) }\end{array}$ & $15.5 \%$ & $31.8 \%$ & $0 \%$ & $0 \%$ & $100 \%$ & $100 \%$ \\
\hline
\end{tabular}


Table 4: Level of compliance to the recommended choice and dose of antibiotic prophylaxis in clean plastic operations

\begin{tabular}{lcc}
\hline \multicolumn{3}{c}{ Frequency and percentages of antibiotics used in clean operations } \\
\hline \multicolumn{3}{c}{ Clean operations - aesthetic } \\
\hline Name and dose of antibiotic & Frequency $n$ (in \%) Primary study & Frequency $n$ (in \%) Re-assessment \\
Ceftriaxone & $21(32)$ & $19(27)$ \\
Cefuroxime 1.5g & $31(48)$ & $22(31)$ \\
Cefuroxime 1g & $1(1.5)$ & $2(3)$ \\
Cefuroxime $\leq 750 \mathrm{mg}$ & $12(18.5)$ & $11(16)$ \\
Cefazolin 1g (recommended) & $0(0)$ & $16(23)$ \\
& Clean operations - uncomplicated burns & \\
\hline Name and dose of antibiotic & Frequency $n$ (in \%) Primary study & Frequency $n$ (in \%) Re-assessment \\
No prophylaxis given & $7(70)$ & $7(47)$ \\
Cefuroxime $\leq 750 \mathrm{mg}$ & $3(30)$ & $3(20)$ \\
Flucloxacillin $1 \mathrm{~g}$ (recommended) & $0(0)$ & $5(33)$ \\
& Clean operations - other clean procedures & \\
\hline Name and dose of antibiotic & Frequency $n$ (in \%) Primary study & Frequency $n$ (in \%) Re-assessment \\
Cefuroxime $1.5 \mathrm{~g}$ & $1(5.6)$ & $3(33)$ \\
Cefuroxime $\leq 750 \mathrm{mg}$ & $2(11.1)$ & $6(67)$ \\
No prophylaxis given (recommended) & $15(83.3)$ & $13(59)$ \\
\hline
\end{tabular}

Choice and dose of antibiotic prophylaxis given in clean operations throughout the study in comparison to recommended choice and dose in local and international guidelines. Table 2 shows more details on guideline standards and compliance levels.

Table 5: Total level of compliance in clean plastic operations

\begin{tabular}{|c|c|c|c|c|c|c|}
\hline \multicolumn{7}{|c|}{ Clean Operations - antimicrobial practices in plastic surgery } \\
\hline \multirow{2}{*}{$\begin{array}{l}\begin{array}{l}\text { Antibiotic } \\
\text { prophylaxis practice }\end{array} \\
\text { Study Period }\end{array}$} & \multicolumn{2}{|c|}{ Aesthetics $n($ in $\%)$} & \multicolumn{2}{|c|}{ Burns $n($ in $\%)$} & \multicolumn{2}{|c|}{ Others $n($ in $\%)$} \\
\hline & $\begin{array}{c}\text { Primary } \\
\text { study }\end{array}$ & $\begin{array}{c}\text { Re- } \\
\text { assessment }\end{array}$ & $\begin{array}{c}\text { Primary } \\
\text { study }\end{array}$ & $\begin{array}{c}\text { Re- } \\
\text { assessment }\end{array}$ & $\begin{array}{c}\text { Primary } \\
\text { study }\end{array}$ & Re-assessment \\
\hline $\begin{array}{l}\text { Total number of } \\
\text { operations }\end{array}$ & 69 & 70 & 10 & 15 & 18 & 22 \\
\hline Given antibiotics & 65/69 (94) & $70 / 70(100)$ & $3 / 10(30)$ & $8 / 15(53)$ & $3 / 18(17)$ & $9 / 22(41)$ \\
\hline Not given antibiotics & $4 / 69(6)$ & $0 / 70(0)$ & $7 / 10(70)$ & $7 / 15(47)$ & $15 / 18(83)$ & $13 / 22(59)$ \\
\hline Correct dose & $\mathrm{n} / \mathrm{a}$ & $16 / 70(23)$ & $\mathrm{n} / \mathrm{a}$ & $5 / 8(63)$ & $\mathrm{n} / \mathrm{a}$ & $\mathrm{n} / \mathrm{a}$ \\
\hline $\begin{array}{l}\text { Adherence to } \\
\text { guidelines } n \text { (in \%) }\end{array}$ & $0 / 69(0)$ & $16 / 70(23)$ & $0 / 10(0)$ & $5 / 15(63)$ & $15 / 18(83)$ & $13 / 22(59)$ \\
\hline
\end{tabular}

Antibiotic prophylaxis compliance in clean plastic surgery operations to local and international guidelines. Table 2 shows more details on guideline standards and compliance levels.

\section{Clean-contaminated and Dirty Procedures}

With regards to clean-contaminated procedures, our facility was not adherent to guidelines during the study period. Three cases of cleft lip/cleft palate were considered within this category; all of given cefuroxime (Table 6). All cases classified as dirty ( 6 during primary study and 9 during reassessment), were adherent to international and local guidelines, as all were treated with antibiotics as therapy depending on culture and sensitivity (Table 6 and 7).
Time of administration of prophylactic antibiotics It is recommended that IV peri-operative antibiotics are to be administered within 1 hour prior to surgical incision according to local hospital guidelines. Within the plastic surgery department in our treatment facility, there was significant noncompliance with regards to this element. Only $11.5 \%$ of operations were adherent to timely administration of antibiotics (Figure 1). The NHS guidelines further recommend that antibiotic prophylaxis is most effective within $30 \mathrm{~min}$ prior to incision, and only 
Time of Administration of Prophylactic Antibiotics

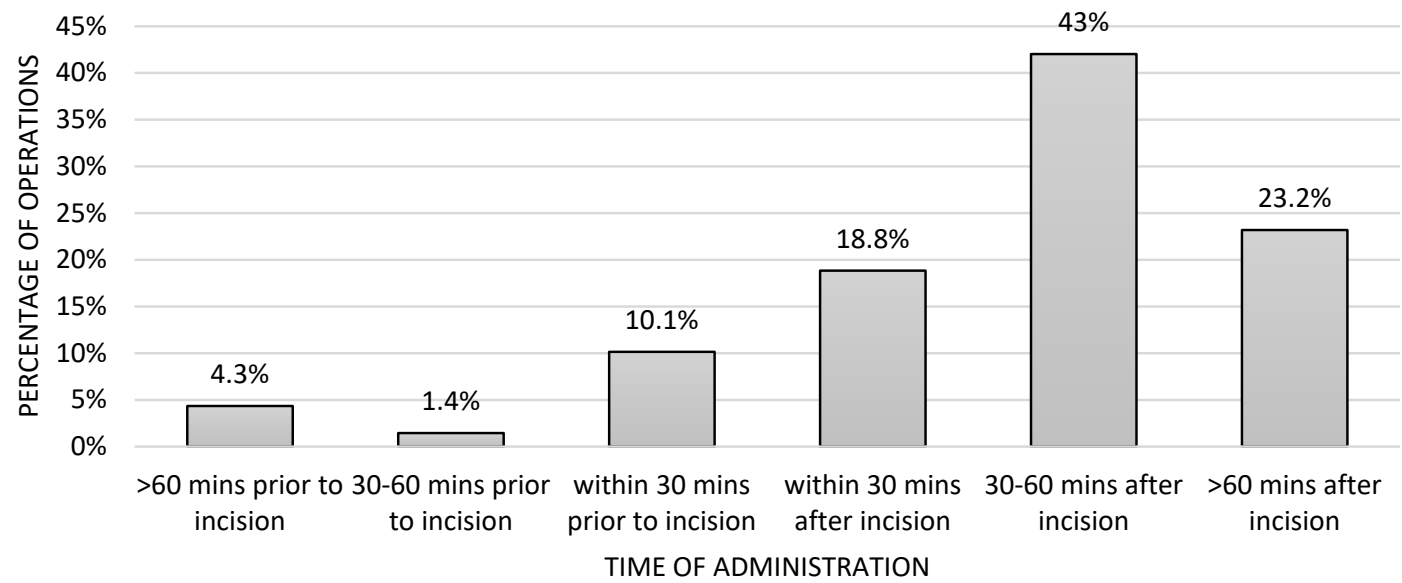

Figure 1: Timing of prophylactic antibiotic administration as observed during the primary study

Table 6: Total level of compliance in clean-contaminated and dirty operations

\begin{tabular}{lcccc}
\hline \multicolumn{3}{c}{ Clean-contaminated and Dirty Operations - antimicrobial practices in plastic surgery } \\
\hline Antibiotic prophylaxis practice & Clean contaminated $n$ (in\%) & \multicolumn{2}{c}{ Dirty $n$ (in\%) } \\
\hline & Primary Study & Re-assessment & Primary Study & Re-assessment \\
\hline Total number of operations & 3 & 1 & 6 & 9 \\
Given antibiotics & $3 / 3(100)$ & $1 / 1(100)$ & $6 / 6(100)$ & $9 / 9(100)$ \\
Not given antibiotics & $0 / 3(0)$ & $0 / 1(0)$ & $0 / 6(0)$ & $0 / 9$ \\
Correct dose & $\mathrm{n} / \mathrm{a}$ & $\mathrm{n} / \mathrm{a}$ & $6 / 6(100)$ & $9 / 9(100)$ \\
Adherence to guidelines $\boldsymbol{n}$ (in \%) & $0 / 3(0)$ & $0 / 1(0)$ & $6 / 6(100)$ & $9 / 9(100)$ \\
\hline
\end{tabular}

Antibiotic prophylaxis compliance in clean-contaminated and dirty plastic surgery operations to local and international guidelines. Table 2 shows more details on guideline standards and compliance levels.

Table 7: Level of compliance to the recommended choice and dose of antibiotic prophylaxis in clean-contaminated and dirty operations

\begin{tabular}{lcc}
\hline \multicolumn{3}{l}{ Frequency and percentages of antibiotics used in selected operations } \\
\hline & Clean-contaminated operations $n$ (in\%) & \\
\hline Name and dose of antibiotic & Primary Study & Re-assessment \\
Cefuroxime 750mg & $3(100)$ & $1(100)$ \\
Co-amoxiclav (recommended) & $0(0)$ & $0(0)$ \\
& Dirty operations - uncomplicated burns $n$ (in\%) & \\
\hline Name and dose of antibiotic & Primary Study & Re-assessment \\
Co-amoxiclav 1.2g & $2(33)$ & $4(44)$ \\
Ceftriaxone 2g & $1(17)$ & $2(23)$ \\
Meropenem 1g & $2(33)$ & $3(33)$ \\
Vancomycin 1g + meropenem 1g tds & $1(17)$ & $0(0)$ \\
\hline Choice and dose of antibiotic prophylaxis given in clean-contaminated and dirty operations throughout the study in comparison to \\
recommended choice and dose in local and international guidelines. Table 2 shows more details on guideline standards and compliance
\end{tabular}

$10.1 \%$ of cases meet this recommendation (Figure $1)$. It is also noteworthy that in $85 \%$ of operations, prophylactic antibiotics were administered after incision, most of given 30-60 min after incision (43\%).

\section{Re-assessment Period}

Following the re-assessment, we observed a significant improvement, with a $36.8 \%$ adherence to the recommendations in total procedures, in comparison with $19.8 \%$ total adherence within the 
primary study (Table 2). Furthermore, there was an increase in adherence to current best practice in our re-assessment by $23 \%$ in aesthetic procedures and $63 \%$ in uninfected burns. We observed a decrease of $19 \%$ adherence in prophylactic antibiotic use within the "other clean procedures" category. Dirty operations observed during the re-assessment had a compliance of $100 \%$ (Table 2). With regards to timely administration of prophylactic antibiotics, $32.6 \%$ of procedures during the re-assessment have met the required standards in comparison to $11.5 \%$ in the primary study (Table 2). The effect of this intervention has been reflected in the decrease of SSI's from $1.8 \%$ in the primary study to $0.08 \%$ in the re-assessment study.

\section{DISCUSSION}

The prescribing practice of prophylactic antibiotics within plastic surgery has been an area of controversy, due to the lack of randomized controlled trials examining the role of prophylactic antibiotics in plastic surgery. Evidence has supported the use of prophylactic antibiotics in various contaminated surgeries and clean breast surgeries ${ }^{18-29}$. Even though abdominoplasties are classified as clean procedures, the use of prophylactic antibiotics is recommended within most guidelines, taking into consideration the prolonged operation time, extensive dissection and significant dead space ${ }^{15}$

We observed a pattern of over-prescribing in elective aesthetic surgeries, including the use of broad-spectrum antibiotics and prescribing a course of antibiotics post-operatively, which could be a result of common practice and surgeon preference to reduce a feared risk of complications in an elective surgery. Similar practice was also noted in a cross-sectional study, surveying surgeons on their prophylactic antibiotic use ${ }^{30}$. In clean aesthetic operations, cefazolin $1 \mathrm{~g}$ IV stat is recommended, yet our hospital had limited supply of the drug. On the other hand, in the majority of the surgeries involving uninfected burns not covered by prophylactic antibiotics, increasing the chances of surgical site infections.

Within our hospital, most antibiotic use that was not adherent to the recommendations was due to the inappropriate choice of the antibiotic being used. For example, according to current best practice, it is recommended that co-amoxiclav for prophylaxis is used for cleft lip/palate procedures. ${ }^{17}$ However, our facility used cefuroxime in most of these operations. More to the point, we observed a preferential tendency towards the use of broad-spectrum antibiotics, especially third generation cephalosporins. Global Point Prevalence Survey of Antimicrobial Consumption and Resistance
(Global-PPS) in 2017 revealed high rates of use of cephalosporins in general at our hospital and third generation cephalosporins in the surgery department in particular, which explain the significantly high use of third generation cephalosporin within our studied population ${ }^{30}$.

The excessively inappropriate use of antibiotics has been a major cause of resistant bacterial strains and Clostridium difficile infections, causing a burden on both the patient and the healthcare system ${ }^{31}$.

Global Antimicrobial Resistance and Use Surveillance System (GLASS) Report published in 2020 by the WHO showed that $64.5 \%$ of patients from Bahrain who had Staphylococcus aureus bacteria isolated from blood samples, had isolates susceptible to oxacillin (a narrow- spectrum b-lactam). This suggests that the use of narrowspectrum beta-lactams such as the recommended flucloxacillin would still be effective in the majority of cases. It was also reported that resistance pattern to cephalosporin included $50 \%$ of E. coli and $45 \%$ of K. pneumoniae. Unfortunately, insufficient data was available to calculate the Drug Resistance Index of cephalosporin in Bahrain ${ }^{18}$. Resistance and sensitivity pattern in the local population needs to be studied for better antibiotic use guidance. It is well-known that the recommended administration of the antibiotic is prior to incision, in order to obtain the required level of antibiotic at the site of surgery ${ }^{19}$. The majority of cases at our hospital received prophylactic antibiotics after the incision was made, creating a risk of surgical site infection.

\section{Quality improvement strategies}

After conducting the primary study, we studied the areas of improvement in our practice. The results of the study were revealed and discussed within the plastic surgery department in the form of a meeting and summary leaflets were distributed to all plastic surgeons for feedback. Weekly summaries of the practice were reviewed in the morning meeting at the end of each week during the implementation period, during which points of improvement and common mistakes were further reinforced. Theatre staff played a role in ensuring that prophylactic antibiotics were given during the recommended time pre-operatively. We included a section on timing of preoperative antibiotic prophylaxis, adopted from the WHO Surgical Safety Checklist, within our local preoperative checklist and the supply of cefazolin was discussed with the pharmacy department.

We observed a deficiency in the recommendation details within our local guidelines in the following areas: burns needing surgical intervention, clean operations not involving grafts or open fractures and clean-contaminated procedures. The importance of adding the mentioned areas within our local 
guidelines were discussed with the head of the plastic surgery department.

\section{LIMITATIONS}

The main limitation to our paper as a retrospective study in the initial phase was the quality of documentation and incomplete records, in some cases. The short duration of time had a significant impact on the number of procedures within each category, with some categories having very limited cases affecting the overall compliance result. A redose of an antibiotic was not considered as most of the operations in our unit and within this study, did not surpass the 3-hour window required an additional dose. Lastly, a larger sample can be used to produce a statistically significant result for future studies.

\section{CONCLUSION}

The main aim of the study was to identify areas of improvement within the current practice of preoperative antibiotic use in the plastic surgery department at our hospital. We achieved an increase of $17 \%$ and $21.1 \%$ in adherence to recommendations regarding choice and time of antibiotics given respectively. The SSI rate decreased from $1.8 \%$ to $0.08 \%$ after the protocol intervention. As a result, we contributed to the development of strategies that would aid in encouraging adherence to the guidelines within our department. The success of implementing our quality improvement strategies was aided by a multidisciplinary approach between plastic surgeons, microbiologists, anesthetists and nursing staff; this included opportunity for regular feedback on current practice and the implementation of the required areas in our local preoperative checklist and guidelines.

\section{ACKNOWLEDGEMENTS}

We would like to acknowledge all those who played a role in the creation of this paper. Special thanks are given to the plastic surgery team members and all extended members of the healthcare team involved in this study. All data was collected and analyzed within the Plastic Surgery Unit in Salmaniya Medical Complex- Bahrain. Mr. Isa Al-Alwani is the first author and supervisor of the project and currently affiliated as a specialist registrar trainee with The Welsh Centre for Burns and Plastic Surgery. Dr Hasan Altahoo is co-first author and currently affiliated as a senior house officer with The Royal Derby Hospital NHS Trust. Dr. Fatema Ahmed Ali is currently affiliated as a senior house officer with The Royal Derby Hospital NHS Trust.
Dr. Fatema Yaqoob is currently affiliated as a general practitioner. Special thanks to Dr. Sadiq Al-Ekri the head of Plastic Surgery and Burns Department in Salmaniya Medical Complex for his close supervision, support and guidance throughout the project.

\section{FINANCIAL DISCLOSURE}

No sources of funds, products, substances, or devices were used in conducting this article. There are no financial or commercial relationships/associations related to any of the authors.

\section{CONFLICT OF INTERESTS}

The authors have no conflicts of interest to declare.

\section{REFERENCES}

1 Gouvêa M, Novaes CO, Iglesias AC. Assessment of antibiotic prophylaxis in surgical patients at the Gaffrée e Guinle University Hospital. Rev Col Bras Cir 2016 Jul-Aug;43(4):225-234.

2 Global Guidelines for the Prevention of Surgical Site Infection. Geneva: World Health Organization; 2018. Available from: https://www.ncbi.nlm.nih.gov/ books/NBK536404/

3 Chole RA, Yee J. Antibiotic prophylaxis for facial fractures. A prospective, randomized clinical trial. Arch Otolaryngol Head Neck Surg 1987;113:10551057

4 Rajan GP, Fergie N, Fischer U, Romer M, Radivojevic V, Hee GK. Antibiotic prophylaxis in septorhinoplasty? A prospective, randomized study. Plast Reconstr Surg 2005; 116:1995-1998

5 Anigian KT, Miller T, Constantine RS, Farkas J, Cortez R, Hein R, Lysikowski JR, Davis KE, Reed G, Kenkel JM. Effectiveness of prophylactic antibiotics in outpatient plastic surgery. Aesthet Surg J 2014 Nov;34(8):1252-8.

6 LaBove G, Davison SP, Jackson MJP, Open RSG. Compliance of Perioperative Antibiotic Dosing and Surgical Site Infection Rate in Office-Based Elective Surgery. 2016;4(5).

7 Stone HH, Hooper CA, Kolb LD, et al. Antibiotic prophylaxis in gastric, biliary and colonic surgery. Ann Surg 1976;184:443-452

8 Collier ZJ, Gottlieb LJ, Alverdy JC. Stochasticity among Antibiotic-Resistance Profiles of Common Burn-Related Pathogens over a Six-Year Period. Surg Infect (Larchmt) 2017 Apr;18(3):327-335.

9 Asokan GV, Ramadhan T, Ahmed E, Sanad H. WHO Global Priority Pathogens List: A Bibliometric Analysis of Medline-PubMed for Knowledge Mobilization 
to Infection Prevention and Control Practices in Bahrain. Oman Med J 2019 May;34(3):184-193.

10 Norfolk and Norwich University Hospitals NHS Foundation Trust (2018) Antibiotic Prophylaxis in Plastics.

11 Buckinghamshire Healthcare NHS Trust. Plastic

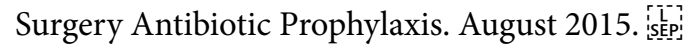

12 Lewis RT. Antibiotic prophylaxis in surgery. Can J Surg 1981;24:561-566.

13 Perrotti J, Castor S, Perez P, Zins J. Antibiotic Use in Aesthetic Surgery: A National Survey and Literature Review. Plastic and Reconstructive Surgery 2002;109(5):1694-1695.

14 Ministry of Health, Salmaniya Medical Complex (2016). Antimicrobilal Guidelines (second edition)

15 Salisbury National Health Service Foundation Trust (2019). Plastic Surgery Antimicrobial Prophylaxis and Treatment.

16 Greater Glasgow National Health Services Foundation Trust. (2018) Antibiotic Prophylaxis for Paediatric Surgery.

17 South Australia Health. (2017). Surgical Antimicrobial Prophylaxis Clinical Guideline (CG269).

18 WHO | Global Health Observatory [Internet]. Apps. who.int. 2020 [cited 31 July 2020]. Available from: https://apps.who.int/gho/tableau-public/tpc-frame. jsp?id=2012

19 Hsu P, Bullocks J, Matthews M. Infection Prophylaxis Update. Semin Plast Surg 2006;20(4):241-248.

20 Ariyan S, Martin J, Lal A, Cheng D, Borah G, Chung $\mathrm{K}$ et al. Antibiotic Prophylaxis for Preventing Surgical-Site Infection in Plastic Surgery. Plastic and Reconstructive Surgery 2015;135(6):1723-1739.

21 Gylbert L, Asplund O, Berggren A, Jurell G, Ransjö U, Ostrup L. Preoperative antibiotics and capsular contracture in augmentation mammoplasty. Plast Reconstr Surg 1990;86:260- 267.
22 Platt R, Zaleznik DF, Hopkins CC, et al. Perioperative antibiotic prophylaxis for herniorrhaphy and breast surgery. N England J Med 1990;322:153-160.

23 Ahmad M, Hussain SS, Malik SA. Perioperative use of antibiotics in cosmetic surgery: A comparison among members of two associations. Gomal J Med Sci. 2009;6:102-105.

24 Kompatscher P, von Planta A, Spicher I, et al. Comparison of the incidence and predicted risk of early surgical site infections after breast reduction. Aesthetic Plast Surg 2003;27:308-314.

25 LeRoy J, Given KS. Wound infection in breast augmentation: The role of prophylactic perioperative antibiotics. Aesthetic Plast Surg 1991; 15:303-305.

26 Platt R, Zucker JR, Zaleznik DF, et al. Prophylaxis against wound infection following herniorrhaphy or breast surgery. J Infect Dis 1992;166:556-560.

27 Serletti JM, Davenport MS, Herrera HR, Caldwell EH. Efficacy of prophylactic antibiotics in reduction mammoplasty. Ann Plast Surg 1994;33:476-480.

28 Veiga-Filho J, Veiga DF, Sabino-Neto M, Amorim MC, Novo NF, Ferreira LM. The role of antibiotics in reduction mammoplasty. Ann Plast Surg 2010;65:144146.

29 Rogers S. Surgical Perspective: Centers for Disease Control and Prevention Guideline for the Prevention of Surgical Site Infection 2017. Surgical Infections. 2017;18(4):383-384.

30 Al Salman J, Al Agha R, Ebrahim Z. Antibiotics Point Prevalence. Bahrain Medical Bulletin 2017;39(4):220224.

31 Amland PF, Andenaes K, Samdal F, et al. A prospective, double-blind, placebo-controlled trial of a single dose of azithromycin on postoperative wound infections in plastic surgery. Plast Reconstr Surg 1995;96:13781383. 